\title{
Orígenes de la crítica nietzscheana del conocimiento a partir del lenguaje
}

\section{Origins of the Nietzschean Critique of Knowledge from the Language}

\author{
Fernando Fava \\ Universidad Nacional de Entre Ríos, Argentina \\ ferjfava@hotmail.com \\ Recibido: 12/05/2015 • Aceptado: 09/02/2016
}

\begin{abstract}
Resumen
Este artículo pretende establecer la génesis de la concepción tropológica del conocimiento en Nietzsche, desde un abordaje histórico-genealógico de los Nachgelassene Fragmente comprendidos entre 1869 y 1873 . Entendemos este trabajo como novedoso, ya que hasta donde alcanzamos a conocer, si bien han sido señaladas por diversos especialistas la centralidad del lenguaje en la comprensión de la crítica nietzscheana a la metafísica y la relevancia del período de juventud para su hermenéutica, no se ha abordado dicha problemática desde un tratamiento de las obras póstumas, tal como aquí se propone. Desde este ángulo, se aprecian nuevas perspectivas para enriquecer los estudios nietzscheanos.
\end{abstract}

Palabras clave: conocimiento, extramoral, lenguaje, metáfora, Nietzsche.

\section{Abstract}

This article seeks to establish the genesis of Nietzsche's tropological conception of knowledge, from both a historical and a genealogical approach to the Nachgelassene Fragmente between 1869 and 1873. We understand this work as somehow original, for as far as we know, even if several scholars have pointed out the centrality of language in order to understand $\mathrm{Ni}$ etzsche's critique to the Metaphysics, as well as the relevance of his early years corpus in his hermeneutics, this issue has not yet been approached 
from the perspective of the posthumous works, as we propose here. From this point of view, new perspectives arise to enrich nietzschean studies.

Keywords: extramoral, knowledge, language, metaphor, Nietzsche. 


\section{Introducción}

Atendiendo a los Nachgelassene Fragmente más juveniles se puede observar el modo en que Nietzsche entendió, tempranamente, que el conocimiento estaba en gran medida vinculado al lenguaje. Fue asumiendo paulatinamente que, para entender el desarrollo histórico de la filosofía, el carácter propio de la cultura y aún la posibilidad misma de conocer, era de vital importancia ocuparse del lenguaje, de su origen, transformación, naturaleza y posibilidades

El siguiente trabajo se introduce en la genealogía de la concepción tropológica del conocimiento, a partir de los Nachgelassene Fragmente de 1869-1873. De este modo, el desarrollo de dicha génesis se estructura en cuatro apartados: en el primero (de 1869 a mediados de 1872), se recogen las primeras preocupaciones en torno al lenguaje fuertemente influenciadas por pensadores enmarcados en el legado del criticismo kantiano; en el segundo (correspondiente al verano de 1872), se observa la búsqueda de un lenguaje propio, problematizando el lenguaje-conocimiento desde su carácter artístico-antropomórfico-superficial; en el tercero (relativo al otoño de 1872), se intenta mostrar la incorporación del paradigma lingüístico como estrategia antimetafísica; en el cuarto (del invierno de 1872 a 1873), se explicita el escenario a partir del cual Nietzsche asume el paradigma tropológico del conocimiento.

Origen de la preocupación en torno al lenguaje-conocimiento. Nachgelassene Fragmente de 1869 a mediados de 1872

Muy tempranamente, en los primeros Nachgelassene Fragmente, ${ }^{1}$ de 1869, encontramos -a partir de la preocupación del joven Nietzsche

1 Las obras de Nietzsche, y los fragmentos póstumos se citan según la edición digital corregida que sigue a la de 1967, con las siglas y referencias usadas en sus aparatos 
en torno a la tragedia griega y su posibilidad de continuidad en el drama - una estructura de abordaje al problema gnoseológico-lingüístico que remite directamente a pensadores inscriptos en el espacio abierto en la filosofía por el criticismo kantiano, ${ }^{2}$ tales como Hartmann, Schopenhauer o Lange. ${ }^{3}$ Una incursión al problema de la función representativa del lenguaje, que en términos generales Nietzsche esquematiza desde dos instancias o niveles: el nivel primario de carácter inconsciente, en el que se asienta el impulso creador y artístico (lo dionisíaco), y el nivel secundario de la conciencia (lo apolíneo). Tal estructuración le permitirá establecer como principio que el lenguaje no encuentra su origen en la conciencia, sino en un nivel oscuro y profundo que la condiciona como lo más real.

Una de las primeras y principales preocupaciones de Nietzsche en la etapa denominada por la crítica como de juventud o «período de Basilea», es que el lenguaje recupere su fuerza vital. Su capacidad de comunicación de los aspectos más profundos de la vida; una riqueza perdida que espera evidenciar desde el abordaje de su aspecto musical, figurativo y gestual. ${ }^{4}$

críticos. Así, cuando se cita una obra, a cada sigla sigue, en cada caso, un número que indica el capítulo o el aforismo correspondiente; o bien, en los casos de los fragmentos póstumos, la sigla es sucedida por el año y la numeración del fragmento. Hay una edición digital corregida disponible en: http://www.nietzschesource.org/

2 Sobre el carácter de la inclusión del pensamiento nietzscheano dentro del espacio abierto por la crítica kantiana, cabe consultar a Jesús Conill (1997) y a Jürger Habermas (1982).

3 En referencia a la relación Lange-Nietzsche, seguimos los lineamientos interpretativos establecidos por el estudio comparado de los textos que ha realizado Sergio Sánchez (1999), el cual asume y, a la vez, nos remite a los trabajos de Jörg Salaquarda Jörg (1979), Gerorge Stack (1983) y los de Giuliano Campioni y Aldo Venturelli (1992).

Asimismo, y dados los límites de este trabajo, para el estudio de la vinculación entre el pensamiento del joven Nietzsche y el pensamiento de Schopenhauer, referimos al excelente y sintético planteamiento de las diversas líneas de investigación que el estudio de dicha relación ha producido: Manuel Barrios Casares (2002) y la precisa y acotada síntesis de dicho influjo referida por Rüdiger Safranski (2001).

Sobre la influencia de Hartmann en la filosofía de Nietzsche durante el período de Basilea, se puede consultar con provecho a Gerratana (1988) quien, a su vez, nos conduce a su vez a los prestigiosos estudios de Claudia Crawford (1988) y a los de Mittasch (1952).

4 Para una exposición del contexto social y político del joven Nietzsche y para una profundización de sus jóvenes inquietudes en torno a la cultura y a la educación (fuertemente vinculadas al proyecto cultural wagneriano), desde la problematización de la 
Se puede observar cómo, desde los escritos más tempranos, Nietzsche comienza precisando, ante quienes reducen el lenguaje a su dimensión meramente conceptual, que si bien respecto a la lengua objetiva, escrita, "el lenguaje significa solo mediante concepto", existe una dimensión de la palabra que "pertenece al mismo tiempo a la música” (eKGWB/NF-1869, 2[10]).

Prestar atención al sonido, ritmo, tiempo e intensidad de las palabras en el lenguaje hablado en el marco de la ópera trágica le permite observar que el lenguaje revela en su faz simbólica el contenido de los sentidos. En la palabra-símbolo hay una traducción o representación de esa melodía originaria que tiene su raíz en los propios afectos, una "transposición de una cosa a una esfera completamente distinta” (eKGWB/NF-1869, 3[20]), una puerta de entrada a los contenidos de los sentimientos (eKGWB/NF-1869, 2[10]). La palabra objetiva-conceptual como "superficie del mar agitado, que es turbulento en las profundidades" se limita a sugerir, a explicitar, la música. A presentarse como un deficiente signo que necesita de la música para expresar el alma de la acción. Las palabras son el lenguaje de la razón, pero la música es el lenguaje que expresa el pathos más íntimo de nuestro ser.

Así, problematizando la capacidad representativa del lenguaje, desde la relación entre lo mimético gestual o lo imaginativo conceptual y el sustrato sonoro-musical de la naturaleza, sostendrá que "la intuición es un producto del instinto" que hunde sus raíces en la sensación (eKGWB/NF-1870, 7 [16]). El carácter figurativo del lenguaje, el ámbito del concepto "es el residuo de la objetivación apolínea de lo dionisíaco” (eKGWB/NF-1871, 9[13]).

El conocimiento se consigue a través de una fuerza inconsciente, de la capacidad artística de constituir formas (eKGWB/NF-1871,16 [13]), de trasponer a partir de los estímulos, no a partir de los conceptos (eKGWB/NF-1871, 16 [6]). El lenguaje se presenta como una suma de conceptos que se revelan como un fenómeno artístico, como la simbolización de exuberantes apariencias, como reflejos (2004), a Paul Janz Curt (1984) y a Rüdiger Safranski (2001). 
apolíneos de un fondo dionisíaco; por lo tanto, siempre una imagen en lugar de la cosa:

Así comienza el hombre con estas proyecciones de imágenes y símbolos. Todas las imágenes artísticas no son más que símbolos, en la pintura, la superficie (eKGWB/NF-1870,8[41]).

\section{Y también:}

Pero ¿qué es lo que simboliza la palabra? Pues, por cierto, nada más que representaciones, sean éstas conscientes o, como sucede la mayoría de las veces, inconscientes: ¿cómo podría corresponder una palabra-símbolo con esa esencia interior, de la que nosotros mismos y el mundo somos imágenes? Ese núcleo solo lo conocemos en forma de representaciones, y únicamente nos es familiar en sus expresiones simbólicas: fuera de esto no hay ningún puente directo que nos conduzca hasta el mismo (eKGWB/NF-1871, 12[1]).

La palabra no traspasa la esfera de la apariencia, sino que, como eco, rebota en la epidermis de dicha esfera: "Pensar y ser no son en absoluto lo mismo. El pensamiento debe ser incapaz de aproximarse al ser y apropiarse de él" (eKGWB/NF-1870,5[92]). Es decir, "Para el hombre no hay ningún camino que lleve a lo Uno primordial. Él es completamente apariencia" (eKGWB/NF-1870, 7 [170]). Pero en el hombre lo Uno primordial vuelve a contemplarse a sí mismo a través de la apariencia. La apariencia revela su esencia. ¿Qué carácter tiene entonces esta relación?

El lenguaje de los conceptos solo refiere al mundo de la apariencia y son ilusiones-símbolos del impulso original que el Uno primordial, la vida, ejerce en los fenómenos, en la naturaleza, para hacer más confortable la existencia. ${ }^{5}$ Esta es la forma originaria de la

5 En consonancia con las tesis heredadas de Lange y Schopenhauer, Nietzsche leerá el mundo ilusorio-apariencial desde la óptica de la vida. De este modo, la vida, mediante el impulso artístico original, genera organismos o formas intelectuales que le permiten afianzarse a sí misma: "Este impulso debe haber dado lugar, en última instancia, a la 
apariencia, un proceso histórico de la voluntad, que desde su escala de sensaciones de placer y displacer aspira a describir la música en imágenes; un proceso que va de los sentidos (sonido) al concepto (imagen) de carácter histórico, que se encuentra prefigurado en el lenguaje.

Ubicando al hombre en el plano de la naturaleza, el de lo fenoménico-apariencial, plano compartido con el resto de los animales y plantas, Nietzsche observa que tanto "las flores de colores y la cola del pavo real se relacionan respecto a su origen lo mismo que la armonía con ese punto de indiferencia, es decir, como la obra de arte con su origen negativo" (eKGWB/NF-1870,7[117]).

La voluntad se expresa mediante la misma «fuerza artística», tanto en el hombre como en la naturaleza en general. Así, como la voluntad genera la belleza en la naturaleza para su conservación y reproducción, también crea en el hombre la belleza de la armonía, de la determinación, de las formas.

La voluntad crea a través del genio artista. "Entonces, todo lo que existe es una imagen de la voluntad, también en la fuerza artística" (eKGWB/NF-1870, 7[117]). En este sentido la "voluntad única del mundo es al mismo tiempo autointuición” (eKGWB/NF1870,7[168]).

Siguiendo muy de cerca a su maestro Schopenhauer en relación con la intuición artística como creadora de las ilusiones necesarias para la vida, se desmarca de éste negándole incluso al genio el acceso al reino primordial: ${ }^{6}$

El placer solo es posible en la apariencia y en la intuición. El sumergirse completamente en la apariencia - es el fin supremo de

estructura del ojo. El intelecto se revela como una consecuencia de un aparato ante todo artístico. El despertar del impulso artístico diferencia a las criaturas animales. Nosotros no compartimos con ningún animal, el hecho de que nosotros veamos, así, la naturaleza artísticamente. Pero hay también una gradación artística de los animales. Ver formas -es el medio de escapar del sufrimiento continuo del impulso. Se crean órganos" (eKGWB/NF-1871,16[13])."

6 "Mi filosofía es un platonismo invertido: cuanto más lejos se está del ente verdadero, tanto más pura, bella y mejor es la vida. La vida en la apariencia como meta" (eKGWB/ NF-1870,7 [156]). 
la existencia: allí donde el dolor y la contradicción no aparecen como existentes-. Nosotros reconocemos la voluntad primordial solo a través de la apariencia; es decir, nuestro conocimiento mismo es un conocimiento representado, o sea, un espejo de un espejo. El genio es lo representado como ejerciendo una pura intuición: ¿qué es lo que intuye el genio? El muro de las apariencias, puramente como apariencias. El hombre, el no-genio, intuye la apariencia como realidad o es representado así: la realidad representada - como el ente representado- ejerce una fuerza semejante a la del ser absoluto: dolor y contradicción" (eKGWB/NF-1870, $7[172]) .^{7}$

De este modo, los elementos que, subrayados de diversas maneras, se mantienen constantes durante este período (del año 1869 a mediados de 1872) se pueden discriminar con claridad desde la idea general de una crítica a la cultura y a la filosofía que, ejercitadas desde la problemática lingüística-epistémica, nos descubren el interés del joven Nietzsche por el arte, la música y el símbolo.

Las posibilidades y limitaciones del lenguaje son abordadas desde una línea romántica que no pudiendo aún despedirse del todo de la «teoría de los dos mundos» conserva aún ciertos parámetros y limitaciones de una perspectiva representacional-correspondentista. Si bien, niega expresamente cualquier posibilidad de conocimiento conceptual de lo «en sí», aún mantiene - con cierta ambigüedad y

7 En este sentido, debemos señalar aquí que, contradiciendo una de sus intuiciones más fuertes en relación al origen del concepto-palabra, Nietzsche no parece poder abandonar el influjo del maestro. Dos fragmentos más abajo, expresa: "El fin del conocimiento es, por consiguiente, un fin estético. Los instrumentos del conocimiento son las imágenes ilusorias". Hasta aquí mantiene una perspectiva compatible con la anterior. Y continúa «retrocediendo» hacia la actitud ascética-contemplativa de las intuiciones, que luego atacará con virulencia: “El fin del mundo es la intuición sin dolor, el placer puramente estético: este mundo de la apariencias se contrapone al mundo del dolor y de la contradicción. Cuanto más profundamente penetra nuestro conocimiento en el ser primordial -que nosotros somos- tanto más se produce también en nosotros la intuición pura de lo Uno primordial. El instinto apolíneo y el dionisíaco están en continuo progreso, el uno toma siempre el estadio del otro y provoca un nacimiento más profundo de la intuición pura" (eKGWB/NF-1870, 7[174]); tesis a la que no volverá e inmediatamente rebatirá, pero que nos ayuda a visualizar el ejercicio de búsqueda que Nietzsche realiza desde los póstumos. 
en sentido negativo- una instancia supra-sensible en el terreno de la estética. La música como arte por excelencia es el principio mismo de toda simbolización que nos habla de un modo generalizado del fondo primordial de la existencia. La «doble naturaleza del lenguaje» suple la inaccesibilidad de la «cosa en sí» por parte del lenguaje conceptual mediante la dimensión sonora del mismo. La más alta posibilidad de significación del lenguaje la tiene el lenguaje de los sonidos simbolizados bajo la figura de Dionisos, cuya expresión más inmediata es la música.

El carácter artístico-antropomórfico del conocimiento. Nachgelassene Fragmente del verano de 1872. Fragmentos 1-173

Nietzsche comprende que, para entender la cultura, el conocimiento y sus posibilidades era necesario enmarcar la problemática en el pathos del hombre teórico (vernünftige Mensch) y su impulso ilimitado de conocimiento; penetrar en las fuentes de un impulso (trieb) que, en su querer saber a toda costa, termina aniquilando la vida. Busca, pues, evidenciar el carácter propio del hombre de ciencias que, continuando los lineamientos de la denominada por Kant «filosofía dogmática», aplica indebidamente las categorías del pensamiento al terreno de lo nouménico, transgrediendo los límites del saber e incursionando indebidamente en el ámbito de la creencia, de la fe.

El interés de este impulso por determinar más allá del campo fenoménico un objeto de culto, de erigir en el vacío cualquier determinación rectora, se presenta como el signo de una vida envejecida, caduca y mezquina (eKGWB/NF-1872, 19[21]) que ha escindido, a partir de Sócrates, la vida en dos mundos. ${ }^{8}$

8 Nietzsche cree ver en Sócrates un «síntoma», un tipo de forma de existencia nunca antes vista: la del «hombre teorético» que se recrea con el velo arrojado y tiene por alta meta los procesos de desvelamiento logrados por su propia fuerza. El saber y el argumento liberan al hombre de lo «espantoso y absurdo del ser»; haciendo aparecer inteligible y, por tanto, justificada la existencia, constituye el prototipo del optimismo teórico que, en su creencia en la posibilidad de escrutar la naturaleza de las cosas, concede al saber y al conocimiento la fuerza de una medicina universal y ve en el error un mal «en sí». Esta representación ilusoria que vino al mundo por primera vez en la persona 
Sócrates rompe con la experiencia mítica del mundo, en la que reina lo inmediato; en lenguaje de Schopenhauer, la «voluntad», reino en el que el hombre se encuentra inmerso en una «única realidad» sin la mediación de una reflexión o crítica. A partir de Sócrates, el mundo se escinde, se crean criterios suprasensibles e inteligibles que conducen la vida y se los ontologiza en un no-lugar. El mundo pierde su carácter inmediato y el hombre empieza a regirse por mediaciones reflexivas ideales.

La razón socrática, que se impone como negación de la vida es responsable del olvido y de la degeneración de los impulsos vitales y de la pérdida de la realidad por parte del lenguaje. Esta crisis muestra cómo el lenguaje es un producto de la metafísica y el lugar en el cual mayormente se manifiesta y estratifican los efectos de la razón como oposición a la vida.

El filósofo del conocimiento trágico como instrumento de la cultura deberá domar el impulso de conocimiento desenfrenado de saber. No mediante una nueva metafísica, ni estableciendo ninguna nueva fe, sino restableciendo los derechos del arte; (eKGWB/NF1872,19 [35]) la capacidad de la «fuerza artística» del «último filósofo» (eKGWB/NF-1872,19[24,27,28,34,35,36]) para dirigir el arte contra el saber: para volver a la vida (eKGWB/NF-1872, 19.[38, 52, 38, 39, 62, 64, 76, 73]).

Contra el pesimismo del saber absoluto del hombre teórico, el filósofo - tal como posteriormente definirá a modo de médico de la cultura- emplea el antídoto del arte (eKGWB/NF-1872,19[52]).

Destacando especialmente la superficialidad y el antropomorfismo como características constitutivas de nuestro entendimiento, a la vez que su incapacidad de rebasar el orden de lo cuantitativo, el joven Nietzsche empieza a experimentar con distintas formas,

de Sócrates, Nietzsche lo expresa magistralmente en su obra acabada de publicar Die Geburt der Tragödie aus dem Geis der Musick, cuyos ecos llegan hasta estos póstumos: "aquella inconcusa creencia de que, siguiendo el hilo de la causalidad, el pensar llega hasta los abismos más profundos del ser, y que el pensar es capaz no sólo de conocer, sino incluso de «corregir» el ser. Esta sublime ilusión metafísica le ha sido añadida como instinto a la ciencia y una y otra vez la conduce hacia aquellos límites en los que tiene que transmutarse en arte: en lo cual es en el que tiene puesta propiamente la mirada este mecanismo" (eKGWB/GT-15). 
buscando precisar y describir las diferentes instancias del proceso del conocimiento.

A partir de la dirección marcada por su maestro Schopenhauer en el ámbito del conocimiento: de los sentidos a los conceptos, Nietzsche retrotrae todo el mundo intelectual hasta el estímulo y la sensación. Tratará de explicar el surgimiento de los procesos conscientes de conocimiento desde la instancia elemental de los sentidos.

Nietzsche retrotrae todo el mundo intelectual hasta el estímulo y la sensación a partir de la dirección marcada por su maestro Schopenhauer en el ámbito del conocimiento: de los sentidos a los conceptos. Tratará de explicar el surgimiento de los procesos conscientes de conocimiento desde la instancia elemental de los sentidos.

El entendimiento como «fuerza artística» superficial, produce las formas mediante la clasificación, el etiquetado y cálculo; midiendo y comparando el material de los sentidos. Componiendo desde "las superficies de las cosas resumidas en el espejo del ojo" permanece ajeno al reino de las cualidades, a cualquier instancia formal, «pura» o esencial (eKGWB/NF-1872, 19[140]). La conciencia, lejos de adentrarse en el ámbito de las cualidades, se limita al campo de las ilusiones, a rozar la superficie. ${ }^{10}$ "Las formas del intelecto se originan a partir de la materia muy lentamente" (eKGWB/

9 En este sentido, podemos leer:

Nuestro entendimiento es una fuerza de superficie, es superficial. A eso se le llama también «subjetivo». El entendimiento conoce mediante conceptos: eso quiere decir que nuestro pensamiento consiste en clasificar, en etiquetar. Por lo tanto, se trata de algo que se reduce a una arbitrariedad del hombre y no a la cosa misma. Solo en el cálculo, y solo en las formas del espacio, el hombre alcanza un conocimiento absoluto, es decir, los límites últimos de todo lo cognoscible son cantidades, y el hombre no comprende ninguna cualidad, sino sólo una cantidad.

¿Cuál puede ser el fin de una tal fuerza de superficie?

Al concepto le corresponde en primer lugar la imagen, las imágenes son pensamientos primordiales, es decir, las superficies de las cosas resumidas en el espejo del ojo.

La imagen es una cosa, la operación aritmética otra.

¡Imágenes en el ojo humano! ¡Esto es lo que domina todo ser humano: desde el ojo! (eKGWB/NF-1872,19 [66]).

10 "Se ha de establecer este principio -vivimos sólo mediante ilusiones- nuestra conciencia roza la superficie" (eKGWB/NF-1872,19[48]). 
NF-1872,19[153]), gracias al operar de una «fuerza artística» que crea la secuencia inferencial, eslabón a eslabón, de la compleja cadena que va del evento más inmediato y elemental de la sensación a las formas abstractas del concepto.

Reproduce una configuración que deja adivinar el modelo schopenhaueriano de los conceptos como «representaciones de representaciones», en el que las últimas -las representaciones intuitivas, es decir: por representaciones abstractas o conceptos- son ya una instancia diferenciada, diferida y radicalmente diversa de la cosa en sí. Nietzsche afirma:

El pensamiento consciente no es más que una selección de representaciones. Hay un largo camino hasta la abstracción. 1) La fuerza que produce la profusión de imágenes, 2) La fuerza que elige y acentúa las imágenes semejantes (eKGWB/NF$1872,19[78])$.

De este modo, se dan dos tipos de potencia artísticas: la que produce imágenes y la que las elige. Este tránsito de una imagen a otra, la transición de las fases inconscientes (intuiciones) al plano de las reflexiones conscientes (conceptos) no es caótico ni arbitrario, sino que está absolutamente determinado y es necesario desde el punto de vista fisiológico. ${ }^{11}$ Nietzsche, siguiendo a la estela compuesta por Lange y negando por lo tanto el recurso kantiano a formas apriori como principios no sensibles de coordinación entre las sensaciones,

11 "Se dan dos tipos de fuerzas artísticas: la que produce imágenes y la que las elige. Esto se demuestra con el mundo onírico: aquí el hombre no continúa hasta la abstracción, o: no es dirigido ni modificado por las imágenes que irrumpen a través del ojo.

Si se considera esta fuerza más de cerca, entonces se ve que tampoco aquí se da un descubrimiento artístico completamente libre: eso sería algo arbitrario, por consiguiente imposible. Pero vista sobre una superficie las irradiaciones más sutiles de la actividad nerviosa: se comportan como las figuras acústicas de Chladni respecto al mismo sonido: tal es la relación entre estas imágenes y la actividad nerviosa que se agita en su base. ¡La vibración y el estremecimiento más delicado de todos! El proceso artístico está absolutamente determinado y es necesario desde el punto de vista fisiológico. Todo pensamiento nos parece a primera vista arbitrario, como sometido a nuestro gusto: no observamos la actividad infinita" (eKGWB/NF-1872, 19[79]). 
hablará de mecanismos inherentes a nuestra organización psicofísica, a la propia fisiología de nuestro aparato perceptivo. ${ }^{12}$

El carácter arbitrario del conocimiento, del pensamiento consciente, se reduce al ámbito de las operaciones de la segunda fuerza artística, al terreno de las designaciones; a la actividad del cerebro que, en relación a la memoria y al material de los sentidos: valora, realza, elige y acentúa las imágenes semejantes. Pero esto es solo la superficie de una actividad nerviosa infinita que se agita en su base. El proceso de génesis de dichas imágenes-conceptos discurre necesariamente desde una especie de «raciocinios inconscientes» que, desde el plano de las intuiciones, de las sensaciones básicas de placer y displacer, extrapolan, concatenan, imágenes, desde un plano fisiológico común y necesario. ${ }^{13}$

12 Es importante, además, tener en cuenta que Nietzsche recoge aquí el problema de la fisiología de los órganos sensoriales; un tema que ocupó a los científicos de la época como Helmhotz, Wundt y Zöllner, y a los que había tenido acceso gracias a la lectura de Lange. Siendo precisamente en Zöllner desde donde el joven Nietzsche se inspira para sus tesis sobre la «sensación».

13 Nietzsche considera de diversas maneras la hipótesis de operaciones de inferencia producidas por la relaciones entre sensaciones, como explicación de la transición de las fases sensoriales inconscientes al plano de la reflexión consciente. Parece no poder encontrar aún una fórmula desde donde poder expresar y esclarecer sus intuiciones más profundas. Observa que hay cierta regularidad en la inconsciencia que no pudiendo atribuirla ni al reflejo de una instancia supra-sensible, ni a la aplicación de cualquier estructura categorial-formal, se inclina, de momento, a atribuirla a la constitución fisiológica de los seres vivos. Pero estas regularidades de cierto carácter lógico, estas determinaciones instintivas-inconscientes de las representaciones de la conciencia, también son objetos de sus más serias dudas. Sospecha de esa regularidad fisiológica. Sospecha acerca de la posibilidad de un planteamiento meramente fisiológico-materialista del conocimiento, pues este, llevado a sus últimas consecuencias no parece ser otra cosa que la transferencia o la reducción a un plano individual de la misma estructura del paradigma contemplativo-representacional del hombre teórico. Parece entender que una reducción de los procesos de formación de las representaciones al plano materialista-fisiológico, no es una alternativa a la propuesta dogmática. Si bien desde aquí se elimina cualquier instancia «en sí» supra-histórica, sigue habiendo una instancia, ahora, instintiva-inconsciente, con las mismas pretensiones de objetividad y determinación.

En consecuencia con estas dudas, Nietzsche expone parte del problema del siguiente modo:

Los «raciocinios» inconscientes despiertan mis sospechas: se tratará de ese tránsito de una imagen a otra: la última imagen alcanzada actúa entonces como estímulo y motivo.

El pensamiento inconsciente debe realizarse sin conceptos, y por lo tanto por «intuiciones». 
Esta fuerza artística-creativa de determinación fisiológica es atribuida por Nietzsche a la naturaleza en general (eKGWB/NF1872,19.[56, 156,158]). Incluso se plantea su posibilidad en la materia inorgánica (eKGWB/NF-1872,19. [54]), reservando la instancia de la segunda fuerza artística para la actividad de lo propiamente humano, para el juego artístico entre las sensaciones, la memoria y el cerebro:

El verdadero material de todo conocimiento está constituido por las más delicadas sensaciones de placer y displacer: el verdadero secreto se encuentra en aquella superficie en la que la actividad nerviosa, consistente en placer y en dolor, señala formas: aquello que es una sensación proyecta al mismo tiempo formas, que luego vuelven a producir nuevas sensaciones.

La esencia de la sensación de placer y displacer se ha de expresar en movimientos adecuados: debido a que estos movimientos adecuados estimulan a otros nervios para la sensación, surge la sensación de la «imagen» (eKGWB/NF-1872,19[84]).

El extraordinario consenso de los hombres sobre las cosas, lejos de comprobar el acceso a cualquier cualidad o la aplicación de

Pero éste es el procedimiento deductivo del filósofo contemplativo y del artista. Éstos hacen lo mismo que cada uno hace en sus movimientos fisiológicos personales, pero trasfiriéndose a un mundo impersonal.

Esta manera de pensar con imágenes no es desde el principio de naturaleza estrictamente lógica, pero sí más o menos lógica. El filósofo se esfuerza entonces en poner en lugar de un pensamiento de imágenes un pensamiento conceptual. Los instintos parecen ser también un tal pensamiento de imágenes, que en definitiva se convierte en estímulo y motivo (eKGWB/NF-1872, 19[107]).

En la misma sintonía, y en referencia a la irreductibilidad de los procesos de formación de los conceptos-palabra al plano meramente materialista-fisiológico, y empezando a intuir la importancia de lo histórico-social (espiritual) en el proceso de formación de los conceptos, leemos: "Pero el lenguaje no ha surgido de repente, sino que es el resultado «lógico» de períodos de tiempo infinitamente más largos. Aquí hay que pensar en el origen del instinto: se desarrolló con mucha lentitud.

La actividad espiritual de milenios depositada en el lenguaje" (eKGWB/NF-1872, 19[117]). 
un marco categorial puro de la razón, ${ }^{14}$ demuestra "la perfecta homogeneidad del aparato receptor" (eKGWB/NF-1872,19[157]). Lo artístico comienza en lo orgánico: "la verdad y la mentira son de orden fisiológico" ("Wahrheit und Lüge physiologisch") (eKGWB/ NF-1872,19[102]).

El elemento antropomórfico en todo conocimiento hace ahora su aparición. "Nuestra salvación no está en el conocer, sino en el crear" (eKGWB/NF-1872, 19[125]). Nuestras representaciones, más allá de las cuales no podemos ir con nuestro intelecto, acentúan lo relativo y antropomórfico, así como la fuerza universalmente dominante de la ilusión (eKGWB/NF-1872,19[37]). ${ }^{15}$ No es solo la vida o la cultura, la que descansa sobre ilusiones, sino también el conocimiento las necesita. La naturaleza de superficie de nuestro intelecto nos revela que "toda figura es algo que pertenece al sujeto" (eKGWB/ NF-1872,19[140]), que "todas las construcciones del mundo son antropomórficas” (eKGWB/NF-1872,19[125]) que "el filósofo es la prolongación del impulso, con el que nosotros, mediante ilusiones antropomórficas, nos relacionamos constantemente con la naturaleza (eKGWB/NF-1872,19[134]).

$\mathrm{Al}$ prestar atención a todos estos fragmentos, se advierte que la preocupación de Nietzsche se concentra en el problema de determinar en sus detalles los complejos mecanismos de la génesis de nuestras representaciones, sin encontrar, al parecer, una fórmula satisfactoria y definitiva. Cabe, no obstante, discriminar con claridad

14 En este sentido, escribe Nietzsche: "El tiempo en sí es absurdo: solo hay tiempo para un ser que siente. Lo mismo hay que decir del espacio. Toda figura es algo que pertenece al sujeto" (eKGWB/NF-1872,19[140]).

15 En este sentido, Nietzsche afirma:

Nada podemos afirmar respecto a la cosa en sí, porque hemos quedado bajo nuestros pies el punto de vista del sujeto que conoce, es decir, del que mide. Una cualidad existe para nosotros, es decir, se mide en nosotros. Si eliminamos la medida, ¿qué queda de la cualidad?

Lo que son las cosas, sin embargo, solo se puede demostrar mediante un sujeto que está junto a ellas y las mide. Sus propiedades no nos interesan en sí mismas, sino en cuanto actúan sobre nosotros.

Ahora hay que preguntar: ¿cómo ha surgido un tal ser que mide?

La planta es también un ser que mide (eKGWB/NF-1872,19[156]). 
tres elementos que, subrayados de diversas maneras, permanecen constantes: i) la inaccesibilidad de la cosa en sí; ii) el carácter artístico y arbitrario de los procesos de nuestro conocimiento consciente se asienta sobre un suelo fisiológico común y necesario; y iii) la ilusoriedad, superficialidad, antropomorfismo de la realidad que conocemos.

Incorporación del paradigma lingüístico. Nachgelassene Fragmente de Otoño de 1872: Fragmentos 174-330

Es notable cómo a partir del fragmento 174, el influjo de la lectura de Die Sprache als Kunst de Gustav Gerber, reorienta la reflexión nietzscheana; ${ }^{16}$ la determinación de las distintas fases de la génesis del conocimiento, su posibilidad y determinaciones, son ahora, abordadas, desde una creciente atención al lenguaje y sus formas. Poco a poco, empezará a apropiarse del paradigma retórico-lingüístico como modelo heurístico de su estrategia antimetafísica. ${ }^{17}$

De este modo, retomando la problemática desde los mismos parámetros de análisis que le ocuparan anteriormente, vuelve, otra vez, a ocuparse del escenario que propició el impulso de conocimiento y a abordar el proceso de formación de las representaciones pero desde las fórmulas del lenguaje; del lenguaje entendido como proceso retórico-artístico.

La caracterización del impulso de conocimiento como pathos del hombre teórico es ahora matizada desde el esclarecimiento de su fuente moral (eKGWB/NF-1872,19[175, 218,219]).

Por naturaleza, el hombre no existe para conocer, "el hombre se ha convertido casualmente en un ser que conoce" (eKGWB/NF$1872,19[179])$.

16 Según figura en el registro de préstamos de la Biblioteca de Basilea, a la cual el joven docente de filología acudía asiduamente durante este período, Nietzsche leyó el primer volumen de la obra de Gerber en el mes de septiembre de 1872 (Sánchez, 1999: 45; Oehler, 1942: 51).

17 Como oportunamente lo señala Luis de Santiago Guervós, "con el descubrimiento de la retórica a Nietzsche se le abría un nuevo camino a modo de crítica antimetafísica frente al conocimiento y al lenguaje conceptual" (2013: 13). 
Dos propiedades necesarias para fines distintos -la «veracidad» y la «metáfora»- han producido la tendencia por la verdad. Por tanto, un fenómeno moral, universalizado estéticamente, produce el impulso intelectual. (eKGWB/NF-1872,19[178]).

La creencia en la verdad se funda en una necesidad de orden social, y en un proceso de construcción de orden estético-fisiológico y de inferencia por analogía, cuyo carácter principal consiste en que lo semejante evoque a lo semejante.

El olvido de que todo conocimiento surge de un endurecimiento y consolidación de un modo de actuar y de pensar surgido de la obligación de ser veraz y universalizado estéticamente desde la metáfora, le ha llevado al hombre a creerse señor del universo.

El impulso de conocimiento surge de la necesidad que impone la sociedad de ser veraces, su origen es casual, no tiene fines universales últimos (eKGWB/NF-1872,19[180, 181]):

El «impulso de verdad» comienza con la observación intensa de cómo se contrapone el mundo verdadero y el de la mentira, y cómo toda vida humana es insegura, cuando la verdad-convención no tiene validez en absoluto: es una convicción moral de la necesidad de una convención fija para que pueda existir una sociedad humana. Si el «estado de guerra» debe cesar en cualquier parte, entonces debe comenzar con la fijación de la verdad, es decir, con una designación válida y vinculante de las cosas.

El mentiroso usa las palabras para hacer que lo irreal aparezca como real, es decir, hace un uso impropio del fundamento sólido (eKGWB/NF-1872,19 [230]).

En este sentido, lenguaje y arte tendrían la misma función vital, es decir, servir y estimular la vida. La verdad, el concepto, nace del acuerdo, del tratado de paz entre los hombres que hace posible la existencia. Por lo tanto, los criterios que rigen el lenguaje y la realidad no son criterios metafísicos, sino más bien antropomórficos y 
pragmáticos. El hombre no quiere la verdad, sino la fe, la confianza en algo (eKGWB/NF-1872, 19 [244]), la verdad sin consecuencia le es indiferente, ${ }^{18}$ le importa más la certeza. "La verdad es fría, la fe en la verdad es poderosa". ${ }^{19}$

El antropomorfismo inherente a todo conocimiento, su superficialidad, y la fuerza o el carácter de traslación implícito en todo conocimiento, es abordado ahora, desde las fórmulas del lenguaje, desde las figuras de los tropos, principalmente desde la «metáfora»y la «sinécdoque».

El modelo representacional del conocimiento, como el camino seguro de la abstracción lógica-necesaria, comienza a ser desplazado por el modelo lingüístico-retórico: artístico y arbitrario.

Nietzsche observa que el proceso de formación de las representaciones puede entenderse a la luz del procedimiento retórico de la traslación de sentido. Desde una transposición de rasgos de nuestra esfera a la esfera de las cosas del mundo: ${ }^{20}$

El único modo de vencer la multiplicidad es que nosotros establezcamos géneros, por ejemplo, clasificar de «audaces» a toda una cantidad de formas de actuar. Nosotros nos las explicamos al ponerlas bajo el título de «audaz». Todo explicar y conocer no son propiamente más que clasificar. -Después de un salto audaz:

18 "La verdad es indiferente al hombre: eso lo demuestra la tautología, como la única forma accesible de la verdad. Así pues, buscar la verdad quiere decir también clasificar correctamente, es decir, subordinar a un concepto dado los casos individuales. [...] Subsumir el mundo entero bajo conceptos correctos no significa otra cosa que ordenar las cosas singulares bajo las formas originariamente humanas más generales de la relación: Así pues, confirmar sólo los conceptos, buscar de nuevo en ellos lo que nosotros ya pusimos en ellos - por lo tanto, esto también es en el fondo una tautología" (eKGWB/NF-1872, 19 [258]).

19 En este sentido, Nietzsche sentencia, textualmente:

¿El filósofo busca la verdad?

No, pues le importaría más la certeza.

La verdad es fría, la fe en la verdad es poderosa (eKGWB/NF-1872, 19 [254]).

20 "El filósofo no busca la verdad, sino la metamorfosis del mundo en los hombres: lucha por comprender el mundo con autoconciencia. Lucha por una «asimilación»: está satisfecho cuando ha dispuesto cualquier cosa antropomórficamente" (eKGWB/ NF-1872,19[237]). 
se protege la pluralidad de las cosas, cuando las consideramos al mismo tiempo como acciones innumerables de una cualidad, por ejemplo, como acciones del agua de Tales. Aquí tenemos nosotros una transposición: una abstracción abarca innumerables acciones y vale como causa. ¿Cuál es la abstracción (propiedad), que abarca la pluralidad de todas las cosas? La cualidad "acuoso", "húmedo". El mundo entero es húmedo, luego el mundo entero es húmedo. ¡Metonimia! Una falsa inferencia. Se cambia un predicado con una suma de predicados (definición)

(...) Todas las figuras retóricas (es decir, la esencia del lenguaje) son raciocinios lógicos falsos. ¡Con ellos comienza la razón! (eKGWB/NF-1872,19[215])

Toda nuestra conceptualización sobre el mundo y la vida, lejos de corresponder a un mundo esencial, es una creación no conducida por leyes lógicas. "Nuestras percepciones sensoriales no se basan en raciocinios inconscientes, sino en tropos" (eKGWB/NF1872,19[217]), en una traslación de sentido a través de lo análogo, de la metáfora. ${ }^{21}$ El proceso del conocimiento consiste en identificar lo semejante con lo semejante desde el fenómeno original de la «confusión». Los sentidos, a través de la metáfora, suscitan la representación de un nexo, una «visión de formas», una analogía (eKGWB/NF-1872,19 [226, 227, 228]). Una imitación (comparación) que presupone una recepción y, luego, una transposición continuada de la imagen recibida en mil metáforas. El inicio de un proceso de abstracción que, como la sinécdoque, reduce la pluralidad a la unidad conceptual:

Hacer caso omiso de lo individual nos proporciona el concepto y con ello comienza nuestro conocimiento: con la clasificación, con la formación de «géneros». Sin embargo, no hay una correspondencia con la esencia de las cosas, se trata de un proceso cognoscitivo que no afecta a la esencia de las cosas. Muchos rasgos

21 "«Metáfora» quiere decir que se trata como «idéntico» algo que se ha reconocido en un punto como semejante" (eKGWB/NF-1872,19 [ 249]). 
particulares nos definen una cosa, pero no todos: la igualdad de estos rasgos nos induce a unir muchas cosas bajo un concepto.

Como «portadores de cualidades» producimos esencias y como causas de esas cualidades producimos abstracciones.

El hecho de que una unidad, un árbol, por ejemplo, se nos presente como una multiplicidad de cualidades, de relaciones, es antropomórfico en un doble sentido: en primer lugar, no existe esta unidad delimitada "árbol", es algo arbitrario delimitar así una cosa (según el ojo, según la forma), toda relación no es la relación verdaderamente absoluta, sino que una vez más está teñida de antropomorfismos (eKGWB/NF-1872,19 [236]).

Todo conocimiento es una producción, una interpretación del mundo a partir de nuestras funciones sensitivas (eKGWB/NF1872,19 [209]). La sensación más generalizada es ya una metáfora (eKGWB/NF-1872,19 [210]), el establecimiento de una relación, de una analogía. Que luego bajo el efecto de lo ilógico, el no saber y el saber erróneo, es extrapolada al reino de las cualidades (eKGWB/ NF-1872,19 [242]) mediante el establecimiento de conceptos generales, los cuales se obtienen mediante la identificación de cosa que son disímiles, mediante el subrayado o realce, selección y clasificación de elementos, o de alguna característica común. Mediante una identificación de lo no-idéntico.

La incorporación del paradigma retórico-lingüístico le permite al joven Nietzsche, no solo exponer de un modo más eficaz la determinación lingüística del pensamiento, sino también realzar el carácter superficial, arbitrario y antropomórfico de todo conocimiento. Mostrando su origen inconsciente, su faz artística-creativa, comienza la restructuración retórica del pensamiento lógico, el modelo representacional del lenguaje es desplazado por un modelo retórico del mismo y las cuestiones filosóficas se convierten en cuestiones retóricas. 
La génesis tropológica del conocimiento. Nachgelassene Fragmente, semestre de invierno de 1873: Darstellung der antiken Rhetorik, Über Wahrheit und Lüge im aussermoralischen Sinne

La toma de contacto con la obra de G. Gerber: Die Sprache als Kunst, a la que acude, en septiembre de 1872 para preparar sus cursos universitarios; le supondrá el encuentro de nuevos argumentos con los que profundizar el quiebre con la impronta metafísica de su pensamiento a la sombra de Schopenhauer. Le proporcionará los medios para expresar sus reflexiones gnoseológicas, en términos que hacen del lenguaje un escenario privilegiado para la verificación de los procesos que llevan a la constitución del mundo como representación.

La tesis central sostenida por Gerber consistente en evidenciar desde el modelo tropológico del arte retórico, el origen sensible del lenguaje y su «esencialidad» metafórica, se le presenta al joven Nietzsche como un valioso instrumento crítico para desenmascarar la ilusión propia del conocimiento, a la vez que le permite una síntesis superadora de las diversas intuiciones y lecturas realizadas hasta el momento.

Para Gerber, la representación conceptual se manifiesta como una producción marcada por la libertad propia de la creación artística. El conocimiento, los conceptos con que opera el lenguaje, son originariamente «tropos», es decir: figuras retóricas, que en su nacimiento configuran una imagen (inapropiada, ilógica y artística), que luego será introducida y estabilizada en el lenguaje. Incluso los conceptos más abstractos se forman siguiendo este proceso que, partiendo de la «cosa en sí» (Ding an sich) alude al «impulso nervioso» (Nervenreiz) el cual provoca la «sensación» (Empfindung) que a su vez se trasforma (como imagen externa) en «sonido» (Laut) y (como imagen interna) en «representación» (Vorstellung) mediante la agrupación de las distintas observaciones de la «cosa en sí». Así, ni aún en el origen del lenguaje, se nos mostraría una esencia de lo «en sí» (an sich) $(1885: 333) .{ }^{22}$

22 Para una mayor profundización en el estudio comparado de la obra de Gerber con los escritos nietzscheanos de este período, se puede consultar a Martin Stingelin (1988), a Anthonie Meijers (1988) o a Sergio Sánchez (1999). 
Muy apegado a estos postulados, Nietzsche ensaya desde los Darstellung der antiken Rhetorik tal preocupación por la génesis del lenguaje:

la retórica tiene una relación mínima con lo verdadero, con la esencia de las cosas; el lenguaje no quiere instruir sino transmitir (übertragen) a otro una emoción y una aprehensión subjetivas. El hombre que configura el lenguaje no percibe cosas o eventos, sino «impulsos» (Reize): él no trasmite sensaciones, sino sólo copias de sensaciones. La sensación, suscitada a través de una excitación nerviosa, no capta la cosa misma: esta sensación es representada externamente a través de una imagen. Pero hay que preguntarse, sin embargo, cómo un acto del alma puede ser representado a través de una imagen sonora (Tonbild). Para que tenga lugar una reproducción completamente exacta, ¿no debería ante todo ser lo mismo el material en el que debe ser reproducido que aquel en el que el alma trabaja? Sin embargo, puesto que es algo extraño - el sonido- ¿cómo puede entonces producirse algo más adecuado que una «imagen»? (De Santiago Guervós, 2013: 91-92).

Estas mismas cuestiones, fuertemente presentes en los Darstellung der antiken Rhetorik, aparecen más sintetizadas y plenamente asimiladas en el contexto de Über Wahrheit und Lüge im aussermoralischen Sinne:

[el creador del lenguaje] se limita a designar las relaciones de las cosas con respecto a los hombres y para expresarlas acude a las más audaces metáforas. ¡En primer término, un estímulo nervioso traspuesto en una imagen! Primera metáfora. ¡La imagen transformada a su vez en un sonido! Segunda metáfora. Y, en cada caso, un salto total de una esfera a otra completamente distinta (eKGWB/WL-1).

Siguiendo los lineamentos básicos de la teoría de las afecciones: el sujeto es estimulado sensitivamente, y mediante analogías, 
establece una «imagen» inadecuada de la cosa, una primera metáfora fruto de la experiencia particular y concreta, desde la cual se opera una segunda traducción a otro tipo de instancia, ya no de los sentidos sino del pensamiento abstracto-conceptual, el cual tiene por objeto la experiencia general. Este segundo universo metafórico sigue siendo una manera inadecuada (que no se presenta como la dogmática adaequatio), una transposición arbitraria, que progresivamente se aleja del canon de certeza, "la enigmática $x$ de la cosa en sí se presenta, en principio como impulso nervioso, después como figura, finalmente como sonido" (eKGWB/WL1).

Comparando la esquematización del marco tropológico propuesto por Gerber y su recepción nietzschena observamos:

En el caso expuesto por Gerber, el proceso es el siguiente:

Cosa en sí (Ding an sich) $\rightarrow$ estímulo nervioso (Nervenreiz) $\rightarrow$ sensación (Empfindung) $\rightarrow$ sonido (Laut) [primera metáfora] $\rightarrow$ representación (Vorstellung) $\rightarrow$ raíz o radical [segunda metáfora] $\rightarrow$ palabra (Wort) $\rightarrow$ concepto (Begriff)

El proceso expuesto por Nietzsche:

Cosa en sí (Ding an sich) $\rightarrow$ estimulo nervioso (Nervenreiz) [primer metáfora] $\rightarrow$ sonido o palabra (Laut o Wort) [segunda metáfora] $\rightarrow$ concepto (Begriff).

Siguiendo la interpretación realizada por Sergio Sánchez, desde la línea hermenéutica de Meijers y Stingelin, destacamos una diferencia crucial entre las respectivas maneras de concebir y presentar las fases del proceso de génesis del lenguaje en la obra de Gerber y en ÜberWahrheit und Lüge im aussermoralischen:

No es solo que Nietzsche presenta una serie más reducida o menos detallada de secuencias, sino que mientras Gerber sitúa la primera metáfora del proceso de génesis del lenguaje entre la sensación y el sonido, Nietzsche la retrotrae un paso más y la sitúa en el primer momento de la percepción, entre la «cosa en 
sí» y el estímulo nervioso. Esto tiene al menos dos implicancias importantes en punto a apreciar la «originalidad» del texto de Nietzsche

1) Para Nietzsche la totalidad del proceso de génesis del lenguaje y no sólo sus fases más avanzadas, es de naturaleza metafórica

2) Lo que para Nietzsche pasa a ocupar el centro de la atención es el problema de la correspondencia o no correspondencia entre nuestro pensamiento y el mundo, esto es, precisamente, el problema de la verdad en sentido extramoral (Sánchez, 1999: 51).

De este modo, "nunca se capta la esencia de las cosas", ni son las cosas las que penetran en la conciencia, sino que somos nosotros los que, estando frente a ellas, captamos mediante la sensación solo una señal (no las cosas mismas) que extrapolamos artísticamente, retóricamente, hacia la expresión lingüística. Así, la representación (como resultado de un proceso artístico-ilógico y arbitrario) está lejos de corresponder fielmente a la percepción originaria, pues constituye una imagen de una imagen de la misma. Pero semejante naturaleza del lenguaje permanece oculta en los usos conscientes-convencionales que hacemos de las palabras y los conceptos; de ahí que sea necesaria una consideración de las dimensiones inconscientes y vivas del lenguaje.

De este modo Nietzsche retrotrae el desarrollo del lenguaje hasta el plano más elemental de la sensación, la cual como resultado de un estímulo nervioso no re-presenta la percepción original, sino que es solo una imagen suya.

Enfrentándose a la teoría correspondentista del conocimiento, del significado de las palabras, Nietzsche plantea el surgimiento de la imagen conceptual desde un doble quiebre o desplazamiento que interrumpen la supuesta continuidad lineal planteada por la tradición. Para Nietzsche, el conocimiento, ya desde la palabra, es representación en el sentido de que no es una imagen-copia, un espejo o calco de la realidad, sino una nueva presentación, o producción del original. 
Ambos pensadores tratarán de evidenciar a partir de dichos planteamientos el carácter artístico del lenguaje, su origen inconsciente y su naturaleza esencialmente metafórico-transpositiva. El lenguaje, las palabras, en su origen, son tropos, es decir, imágenes inapropiadas originadas artísticamente, a partir de un proceso no regido por leyes lógicas, sino, por el contrario, por saltos ilógicos, así como por extrapolaciones y equiparaciones esencialmente arbitrarias. ${ }^{23}$

Es imposible, por lo tanto, llegar mediante el lenguaje a describir la realidad. El lenguaje no transmite más que un contenido subjetivo, la impronta del hombre que como «artífice del lenguaje», lejos de adentrarse a un mundo esencial, se maneja con sensaciones y copias de sensaciones.

El lenguaje es una obra de arte construida por «tropos» y figuras que establece el individuo y que luego mediante el uso común se estabilizan en figuras gramaticales, en conceptos abstractos:

Hablando con propiedad, todo lo que normalmente se llama discurso es figuración. El lenguaje es la creación de artistas individuales del lenguaje, pero lo que lo fija es la elección operada por el gusto de la mayoría (Darstellung der antiken Rhetorik: $§ 427$. En De Santiago Guervós, 2013).

Esquemas figurativos que no tienen por fin adentrarse en una verdad eterna, sino relacionar, estructurar, «dar sentido» a lo real. En definitiva, el lenguaje no transmite más que un contenido subjetivo; el hombre como «artífice del lenguaje», lejos de adentrarse a un mundo esencial, se maneja con sensaciones y copias de sensaciones. La verdad nace en la impresión subjetiva nerviosa siendo luego catapultada mediante la estructura del lenguaje a verdades lógicas conceptuales, a figuras gramaticales, que posteriormente avaladas por el consenso social, se constituirán en «verdad».

23 Luis de E. Santiago Guervós sintetiza la relación entre ambos pensadores del siguiente modo: "En resumen, se puede decir que las ideas fundamentales que Nietzsche sostiene con Gerber son: que el lenguaje es una especie de arte inconsciente; que la génesis del lenguaje va de imagen en imagen; la idea de que las palabras son desde el comienzo tropos; que el lenguaje es esencialmente metafórico y, finalmente, que es imposible que el lenguaje puede describir la realidad" (2013: 18). 
Como hemos podido observar, las reflexiones de Nietzsche respecto al lenguaje se retrotraen o están presentes en el origen mismo de sus más tempranas meditaciones. De un modo muy intuitivo, con fórmulas heredadas, Nietzsche va combinando su bagaje cultural con lecturas de pensadores de cuño crítico como Lange o Hartmann; ensayando su propio pensamiento desde bocetos no exentos de vaguedades y contradicciones, como también repleto de intuiciones geniales. A partir del verano del 72, los Nachgelassene Fragmente exponen de una manera clara no solo cómo poco a poco se va difuminando el legado romántico, sino también el empleo de un lenguaje diferente. Incluso los temas, como el modo de radicalizar los problemas, denotan un cambio, un giro en sus consideraciones. El arte y la estética adquieren una nueva dimensión, la explicación del lenguaje desde el «símbolo», prácticamente, desaparece. Las oposiciones categoriales que, hasta ahora, habían contribuido a mantener el armazón central de sus ideas: Apolo/Dionisos, música/lenguaje, Verdad/apariencia, son mencionadas ya solo ocasionalmente, hasta desaparecer por completo. El problema del lenguaje, mientras tanto, adquiere un protagonismo especial, remarcando su dimensión fisiológica, ilusoria y artística, su «carácter de superficie», su antropomorfismo. Nietzsche comienza a esbozar los lineamientos generales de lo que luego se convertiría en método de análisis, indagación y auscultación de la cultura; se retrotrae genealógicamente al surgimiento de los elementos básicos de la conformación del conocimiento. Consecuentemente, sus notas se orientan hacia el esclarecimiento de los «procesos» de formación de las representaciones.

En el otoño del mismo año, profundiza dicha crítica desde la asunción del paradigma retórico-lingüístico como estrategia antimetafísica que remite la verdad a su dimensión pragmática-social, asumiendo definitivamente, a partir del invierno 1872-1873, el paradigma tropológico del conocimiento a partir de la recepción de Gerber. De este modo, los fragmentos póstumos comprendidos entre el verano de 1872 y 1873, se nos presentan como la antesala 


\section{inmediata, el punto de inflexión, que nos conduce a lo que podría- mos considerar una visión propiamente nietzscheana.}

\section{Referencias bibliográficas}

Barrios Casares, M. (2002). "La crítica de la «cosa en sí» en la filosofía del joven Nietzsche”. En Voluntad de lo trágico. El concepto nietzscheano de voluntad a partir de El Nacimiento de la Tragedia. Madrid: Biblioteca Nueva.

Campioni, G. y A. Venturelli (eds.). (1992). "Nietzsche e Lange”. En La «Biblioteca ideale» di Nietzsche, pp. 19-43. Napoli: Guida.

Conill, J. (1997). "Por los caminos del criticismo kantiano". En El poder de la mentira. Nietzsche y la política de la transvaloración. Madrid: Tecnos.

Crawford, C. (1988). The Beginning of Nietzsche’s Theory fo Language. Berlín:Walter de Gruyter.

De Santiago Guervós, L.E. (2013). “Introducción”. En Friedrich Nietzsche. Escritos sobre retórica. Madrid: Trotta.

De Santiago Guervós, L.E. (1994). Nietzsche y la polémica sobre El Nacimiento de la Tragedia. Málaga: Hybris.

Esteban Enguita, J. (2004). "Influencia ideológicas sobre el pensamiento político del joven Nietzsche: La Kultur y la vanguardia intelectual de la burguesía alemana”. En El joven Nietzsche. Política y tragedia. Madrid. Biblioteca Nueva.

Gerber, G. (1885). Die Sprache als Kunst, 2 vols. Bromberg: Mittler'sche Buchhandlung 1871-1874; 2da. ed. Berlín: R. Gärtner's Verlag.

Gerratana F. (1988). „Der Wahn jenseit des Menschen, Zur frühen Eduard von Hartmann-Rezeption Nietzsche”. En Nietzsche Studien, XVII, pp. 391-433.

Habermas, J. (1982). “La crítica nihilista del conocimiento en Nietzsche”. En Sobre Nietzsche y otros ensayos. Madrid: Tecnos.

Janz, C.P. (1981). Friedrich Nietzsche Vol I: Infancia y juventud. Madrid. Alianza.

Oehler, M. (1942). “Apéndice 2". Verzeichnis der von Nietzsche aus der Universitätbibliothek in Basel 1869-1879. En Nietzsche Archivs, 51.

Meijers, A. (1988). „Gustav Gerber und Friedrich Nietzsche. Zum historischen Hintergrund der sprachphilosophichen Auffassungen des frühen Nietzsche”. En Nietzsche Studien, 17, pp. 369-390.

Mittasch A. (1952). Nietzsche als Naturphilosoph. Stuttgart: Alfred Kröner. 
Nietzsche, F. (1967). Werke, Kritische Gesamtausgabe, herausgegeben von G. Colli und M. Montinari. G. Colli, M. Montinari. Berlín: De Gruyter.

Nietzsche, F. 1994. Sobre verdad y mentira en sentido extramoral, Madrid: Tecnos. Traducción de Luís Valdés y Teresa Orduña.

Nietzsche, F. (2010). Fragmentos póstumos I (1869-1874). L.E. Santiago de Guervós (trad.). Madrid: Tecnos.

Safranski, R. (2001). Nietzsche. Biografía de su pensamiento. Barcelona:Tusquets.

Salaquarda, J. (1979). „Der Standpunkt des Ideals bei Lange und Nietzsche”. En Studi Tedeschi, XXII(1) Napoli.

Sánchez, Sergio. 1999. El problema del conocimiento en el joven Nietzsche. Los póstumos del período 1867-1873. Córdoba, Arg. Universitas.

Stack, George. 1983. Lange and Nietzsche, Walter de Gruyter, Berlin-New York.

Stingelin, Martin. 1988. „Nietzsches Wortspiel als Reflexion auf poet(olog)ische Verfahren”. En Nietzsche Studien, 17, pp. 337-349. 